DE CASTRO, André Giovane; FORNASIER, Mateus de Oliveira, Benedito Silva e DE MELLO, Larissa Fernandes Ranieri. Leis brasileiras e atuação dos tribunais quanto à possibilidade de indenização contra danos à privacidade do indivíduo. Revista Eletrônica Direito e Política, Programa de PósGraduação Stricto Sensu em Ciência Jurídica da UNIVALI, Itajaí, v.10, n.4, 30 quadrimestre de 2015. Disponível em: www.univali.br/direitoepolitica - ISSN 1980-7791.

\title{
LEIS BRASILEIRAS E ATUAÇÃO DOS TRIBUNAIS QUANTO À POSSIBILIDADE DE INDENIZAÇÃO CONTRA DANOS À PRIVACIDADE DO INDIVÍDUO
}

\author{
BRAZILIAN LAW AND PRACTICE COURTS OF THE POSSIBILITY OF \\ DAMAGES AGAINST INDEMNITY TO PRIVACY GUY
}

\author{
André Giovane de Castro ${ }^{1}$ \\ Mateus de Oliveira Fornasier ${ }^{2}$
}

SUMÁRIO: Introdução; 1 . Direitos da Personalidade no Ordenamento Jurídico Brasileiro; 2. Privacidade do Usuário na Rede Mundial de Computadores; 3. Posicionamento dos Tribunais Superiores; Considerações Finais; Referências das Fontes Citadas.

\section{RESUMO}

O presente artigo científico busca analisar a forma como o direito à privacidade, integrante dos direitos da personalidade, encontra-se inserido no ordenamento jurídico brasileiro. Com o advento da Constituição Federal de 1988, os sujeitos receberam atenção especial e, em virtude disso, surge a necessidade de refletir sobre o modo como o sistema judiciário está atendendo às demandas. A partir do método hipotético-dedutivo, com pesquisa doutrinária e jurisprudencial, compreende-se que uma era dominada pela informação merece reflexão acerca do limite de informar e a discussão entre o conflito de liberdade de expressão e privacidade, ambos direitos constitucionais, onde nota-se que os julgadores tendem a priorizar o respeito ao indivíduo. Objetiva-se, pois, constatar a atuação dos tribunais nas causas que versam sobre essa matéria, bem como analisar os textos legais que regulam o direito à privacidade.

\footnotetext{
${ }^{1}$ Aluno do Curso de Graduação em Direito da Universidade Regional do Noroeste do Estado do Rio Grande do Sul (UNIJUÍ), em Três Passos/RS/Brasil. E-mail: andre_castro500@hotmail.com

2 Doutor e Mestre em Direito Público pela Universidade do Vale do Rio dos Sinos (UNISINOS). Professor dos Cursos de Graduação em Direito e Mestrado em Direitos Humanos da Universidade Regional do Noroeste do Estado do Rio Grande do Sul (UNIJUÍ), de Ijuí/RS/Brasil. E-mail: mateus.fornasier@unijui.edu.br
} 
DE CASTRO, André Giovane; FORNASIER, Mateus de Oliveira, Benedito Silva e DE MELLO, Larissa Fernandes Ranieri. Leis brasileiras e atuação dos tribunais quanto à possibilidade de indenização contra danos à privacidade do indivíduo. Revista Eletrônica Direito e Política, Programa de PósGraduação Stricto Sensu em Ciência Jurídica da UNIVALI, Itajaí, v.10, n.4, 30 quadrimestre de 2015. Disponível em: www.univali.br/direitoepolitica - ISSN 1980-7791.

PALAVRAS-CHAVE: Personalidade; Privacidade; Internet; Brasil; Tribunais. ABSTRACT

This scientific paper is to analyze how the right to privacy, a member of personal rights, is inserted into the Brazilian legal system. With the advent of the 1988 Federal Constitution, the subjects were given special attention and, because of that, there is a need to reflect on how the judicial system is meeting the demands. From the hypothetical-deductive method, doctrinal and jurisprudential research, it is understood that an era dominated by information deserves reflection on the limits of information and discussion between the conflict of freedom of expression and privacy, both constitutional rights where note- that the judges tend to prioritize respect for the individual. The objective is therefore to note the role of the courts in cases that deal with this matter and to examine the legal texts governing the right to privacy.

KEYWORDS: Personality; Privacy; Internet; Brazil;Courts.

\section{INTRODUÇÃO}

A pesquisa tem o objetivo de analisar a forma como o direito à privacidade, integrante dos direitos da personalidade, está regulado no ordenamento jurídico brasileiro e a sua eficácia nas decisões dos tribunais, pois se trata de uma norma que visa garantir aos seres humanos, enquanto sujeitos de direito, a preservação de dados e fatos que julgam serem da esfera íntima. Nesse tocante, segundo Diogo Leite de Campos $^{3}$, os direitos personalidade constituem-se como tutela jurídicas para proteção do próprio indivíduo.

O direito da privacidade surge no Brasil, com maior ênfase, a partir da promulgação da Constituição Federal de 1988, determinando no artigo 50, X, que "são invioláveis a intimidade, a vida privada, a honra e a imagem das pessoas, assegurado o direito à indenização pelo dano material ou moral decorrente de sua violação" ${ }^{4}$. De modo específico, o Código Civil de 2002 elenca em seu artigo

3 CAMPOS, Diogo Leite de. Lições de Direito da Personalidade. 2 ed. Coimbra: Universidade de Coimbra, 1992.

4 BRASIL. Constituição da República Federativa do Brasil de 1988. Brasília: Senado Federal, Subsecretaria de Edições Técnicas, 2012. 
DE CASTRO, André Giovane; FORNASIER, Mateus de Oliveira, Benedito Silva e DE MELLO, Larissa Fernandes Ranieri. Leis brasileiras e atuação dos tribunais quanto à possibilidade de indenização contra danos à privacidade do indivíduo. Revista Eletrônica Direito e Política, Programa de PósGraduação Stricto Sensu em Ciência Jurídica da UNIVALI, Itajaí, v.10, n.4, 30 quadrimestre de 2015. Disponível em: www.univali.br/direitoepolitica - ISSN 1980-7791.

11: "Com exceção dos casos previstos em lei, os direitos da personalidade são intransmissíveis e irrenunciáveis, não podendo o seu exercício sofrer limitação voluntária" ${ }^{5}$.

Após um longo período da história da humanidade em que o viés central do Direito era proteger o patrimônio, legisladores e juristas repensaram a tutela conferida aos próprios sujeitos e, assim, instituíram um dispositivo de respeito à privacidade. Criou-se, diante disso, uma nova fase do Direito em razão da crescente demanda de ações decorrentes da era da informação, com foco na rede mundial de computadores.

A partir do método hipotético-dedutivo, analisa-se neste artigo, à vista disso, os dispositivos legais existentes no Brasil que versam sobre o direito à privacidade e a eficácia dos tribunais na sua efetivação. Almeja-se, ainda, discorrer sobre os desafios impostos pela rede mundial de computadores à proteção do indivíduo enquanto sujeito de direito.

\section{DiREITOS DA PERSONALIDADE NO ORDENAMENTO JURÍDICO BRASILEIRO}

O Brasil, desde a promulgação da Constituição Federal de 1988, vive um novo modelo basilar de Direito. A sociedade, enquanto grupo formador do Estado Democrático de Direito, demandou um olhar diferenciado do sistema jurídico para as suas necessidades. O mundo globalizado e o avanço da tecnologia são os fatores primordiais para o desenvolvimento de uma nova área de direitos.

Se no decorrer de muitos anos a legislação privada tinha como essência zelar pelo contrato, propriedade, família e herança, o final do século XX trouxe a obrigação de legisladores e juristas repensarem a tutela dada aos próprios

${ }^{5}$ BRASIL. Código Civil e Constituição Federal e legislação complementar: miniobra coletiva de autoria da Editora Saraiva com a colaboração de Luiz Roberto Curia, Livia Céspedes e Juliana Nicoletti. 21 ed. São Paulo: Saraiva, 2015. 
DE CASTRO, André Giovane; FORNASIER, Mateus de Oliveira, Benedito Silva e DE MELLO, Larissa Fernandes Ranieri. Leis brasileiras e atuação dos tribunais quanto à possibilidade de indenização contra danos à privacidade do indivíduo. Revista Eletrônica Direito e Política, Programa de PósGraduação Stricto Sensu em Ciência Jurídica da UNIVALI, Itajaí, v.10, n.4, 30 quadrimestre de 2015. Disponível em: www.univali.br/direitoepolitica - ISSN 1980-7791.

sujeitos. Constatou-se que não era suficiente, com ênfase a uma coletividade enraizada na informação, tratar a lei somente com o objetivo patrimonialista, mas, também, abarcar a personalidade do agente no que tange à vida, à intimidade, à honra, à integridade física, entre outros.

\subsection{Matéria tratada nos textos constitucionais}

Na segunda metade do século $\mathrm{XX}$, diversos textos normativos regularam o direito à privacidade. Essa discussão foi, diante disso, também inserida no Brasil. Segundo José Adércio Leite Sampaio:

Diversos textos constitucionais promulgados a partir dos anos 70 consagram expressamente o direito à intimidade e à vida privada, não apenas sob a fórmula clássica, de proteção da inviolabilidade do domicílio e das comunicações, mas também, ao que chamaremos de textos constitucionais de segunda geração, declarando em cláusula geral os valores da intimidade e vida privada, e, em terceira geração, tutelando-as diante dos riscos da informática ${ }^{6}$.

É possível destacar, a partir desse raciocínio, alguns textos constitucionais promulgados nas últimas décadas, principalmente no final do século passado, que incorporaram os direitos da personalidade, com foco à inviolabilidade da intimidade e da vida privada. Entre eles, merecem destaque a Constituição Portuguesa de 1976, a Constituição Espanhola de 1978 e a Constituição Brasileira de 1988. Os ordenamentos jurídicos, dessa forma, passam a proteger todos os atributos inerentes à pessoa. Conforme Gagliano e Pamplona, "conceituam-se os direitos da personalidade como aqueles que têm por objeto os atributos físicos, psíquicos e morais da pessoa em si e em suas projeções sociais"7.

\footnotetext{
6 SAMPAIO, José Adércio Leite. Direito à intimidade e à privacidade: uma visão jurídica da sexualidade, da família, da comunicação e informações pessoais, da vida e da morte. Belo Horizonte: Del Rey. p. 112.

7 GAgliano, Pablo Stolze; FILHO, Rodolfo Pamplona. Novo curso de Direito Civil: parte geral 1. 16 ed. São Paulo: Saraiva, 2014, p, 186.
} 
DE CASTRO, André Giovane; FORNASIER, Mateus de Oliveira, Benedito Silva e DE MELLO, Larissa Fernandes Ranieri. Leis brasileiras e atuação dos tribunais quanto à possibilidade de indenização contra danos à privacidade do indivíduo. Revista Eletrônica Direito e Política, Programa de PósGraduação Stricto Sensu em Ciência Jurídica da UNIVALI, Itajaí, v.10, n.4, 30 quadrimestre de 2015. Disponível em: www.univali.br/direitoepolitica - ISSN 1980-7791.

\subsection{Privacidade à luz do princípio da dignidade da pessoa humana}

A lei é direcionada a pensar na valorização do ser humano enquanto indivíduo constituído de direitos. Essa temática encontra base sólida na Constituição Federal de 1988, em seu artigo 10, III, que determina a dignidade da pessoa humana como fundamento da República. Esse princípio surge com os estudos de Immanuel Kant, filósofo prussiano, que tinha a percepção de que a pessoa deveria ser tratada como um fim em si própria, e não como um meio, ou seja, objeto.

De acordo com Kant apud Nicolodi:

O homem, e duma maneira geral todo o ser racional, existe como um fim em si mesmo, não como meio para o uso arbitrário desta ou daquela vontade. Pelo contrário, em todas as suas funções, tanto nas que se dirigem a ele mesmo, como nas que se dirigem a outros seres racionais, ele tem sempre de ser considerado simultaneamente como um fim $^{8}$.

O teor do supracitado princípio fundamental é, hoje, utilizado para constituir embasamento aos direitos individuais e sociais. Essa constatação decorre, conforme Sarlet, pois "é o Estado que existe em função da pessoa humana, e não o contrário, já que o homem constitui a finalidade precípua, e não o meio da atividade estatal ${ }^{\prime \prime}$.

\subsection{Determinação do direito à privacidade na Constituição Federal de} 1988 e no Código Civil de 2002

A Carta Magna de 1988 determina em seu artigo 50, X: "São invioláveis a intimidade, a vida privada, a honra e a imagem das pessoas, assegurado o direito à indenização pelo dano material ou moral decorrente de sua violação"10.

\footnotetext{
8 NICOLODI, Márcia. Os direitos da personalidade e a proteção da dignidade da pessoa humana. Ijuí: Unijuí, 2003, p. 57.

9 NICOLODI, Márcia. Os direitos da personalidade e a proteção da dignidade da pessoa humana. p. 58.

${ }^{10}$ BRASIL. Constituição da República Federativa do Brasil de 1988.
} 
DE CASTRO, André Giovane; FORNASIER, Mateus de Oliveira, Benedito Silva e DE MELLO, Larissa Fernandes Ranieri. Leis brasileiras e atuação dos tribunais quanto à possibilidade de indenização contra danos à privacidade do indivíduo. Revista Eletrônica Direito e Política, Programa de PósGraduação Stricto Sensu em Ciência Jurídica da UNIVALI, Itajaí, v.10, n.4, 30 quadrimestre de 2015. Disponível em: www.univali.br/direitoepolitica - ISSN 1980-7791.

A partir da positivação dessa norma, os direitos da personalidade alcançaram o nível constitucional, com a ideia de que se configuram como essenciais, como visto, à dignidade da pessoa humana.

Apesar de ser definido na Constituição, faltava regular no Direito Civil, uma vez que restava a necessidade de disciplinar a matéria no Código Civil. Em seu aspecto específico, portanto, o Brasil trouxe ao ordenamento os direitos da personalidade no Código Civil de 2002. Além do texto constitucional, ela é dotada legalmente no artigo 11 da Lei 10.406/2002: "Com exceção dos casos previstos em lei, os direitos da personalidade são intransmissíveis e irrenunciáveis, não podendo o seu exercício sofrer limitação voluntária" ${ }^{11}$. Trata-se, à vista disso, de um direito que não pode ser exercido por outro senão o titular, assim como não é possível ao sujeito renunciá-lo.

O Estado brasileiro, à vista disso, deu início a uma nova conjuntura de direitos, almejando promover o respeito à privacidade do sujeito. A crescente demanda nesse aspecto fez com que juristas e legisladores dessem atenção a um novo modelo normativo, que viesse a consagrar efetivamente o próprio princípio supremo da Constituição Federal, qual seja, a dignidade da pessoa humana.

\section{PRIVACIDADE DO USUÁRIO NA REDE MUNDIAL DE COMPUTADORES}

A era dos sistemas de informação, principalmente no que se refere à rede mundial de computadores, exige que o Direito configure uma proteção aos cidadãos, uma vez que eles, como usuários e parte hipossuficiente, estão à mercê de uma infinidade de lesões a sua personalidade. Nesse tocante, corrobora Gagliano e Pamplona que "com os avanços tecnológicos, os atentados à intimidade e à vida privada, inclusive por meio da rede mundial de

\footnotetext{
${ }^{11}$ BRASIL. Código Civil e Constituição Federal e legislação complementar: miniobra coletiva de autoria da Editora Saraiva com a colaboração de Luiz Roberto Curia, Livia Céspedes e Juliana Nicoletti.
} 
DE CASTRO, André Giovane; FORNASIER, Mateus de Oliveira, Benedito Silva e DE MELLO, Larissa Fernandes Ranieri. Leis brasileiras e atuação dos tribunais quanto à possibilidade de indenização contra danos à privacidade do indivíduo. Revista Eletrônica Direito e Política, Programa de PósGraduação Stricto Sensu em Ciência Jurídica da UNIVALI, Itajaí, v.10, n.4, 30 quadrimestre de 2015. Disponível em: www.univali.br/direitoepolitica - ISSN 1980-7791.

computadores (internet), tornaram-se muito comuns" ${ }^{12}$. A proximidade com pessoas desconhecidas, em muitos casos, promove mais um desafio ao sistema jurídico, que é o de garantir uma tutela específica a quem tiver seu direito violado, assim como punir quem, sob função ou cargo, divulgar dados confidenciais de outrem.

\subsection{Lei 12.965/14 e a regulação da sociedade virtual}

Com base na modificação estrutural em que a sociedade vive conectada virtualmente, em 2014 foi sancionada a Lei 12.965, que institui o Marco Civil da Internet. Após um profundo debate entre parlamentares de oposição e situação, elaborou-se, com auxílio da sociedade civil, uma lei com o intuito de regular o uso da internet no País, de forma a determinar princípios, garantias, direitos e deveres para quem utiliza e oferece serviços a ela relacionados.

A privacidade, à luz desse recente diploma legal, é considerada um dos princípios norteadores do eficiente uso e finalidade da chamada rede mundial de computadores. Uma vez que esse instrumento tecnológico possibilita a troca de informações e, ao mesmo tempo, a sua guarda, quem disponibiliza esse serviço à coletividade deve assegurar a privacidade, garantindo segurança aos clientes.

Diogo Leite de Campos ${ }^{13}$ colabora ao dizer que, enquanto direitos da personalidade, as garantias à intimidade e à privacidade são dispositivos reconhecidos pelos juristas como direitos da pessoa. Dessa forma, destaca que o Direito deve limitar e reconhecer o indivíduo, ao mesmo tempo em que declara seus respectivos direitos.

Os direitos da personalidade são constituídos de várias vertentes, entre eles a privacidade, que encontra amparo legal, como supramencionado, na Constituição Federal, no Código Civil e no Marco Civil da Internet. A partir do instituto de consolidação do ambiente virtual, surge o Direito Digital para promover o

${ }^{12}$ GAgliano, Pablo Stolze; FILHO, Rodolfo Pamplona. Novo curso de Direito Civil: parte geral 1. p. 221.

${ }^{13}$ CAMPOS, Diogo Leite de. Lições de Direito da Personalidade. 
DE CASTRO, André Giovane; FORNASIER, Mateus de Oliveira, Benedito Silva e DE MELLO, Larissa Fernandes Ranieri. Leis brasileiras e atuação dos tribunais quanto à possibilidade de indenização contra danos à privacidade do indivíduo. Revista Eletrônica Direito e Política, Programa de PósGraduação Stricto Sensu em Ciência Jurídica da UNIVALI, Itajaí, v.10, n.4, 30 quadrimestre de 2015. Disponível em: www.univali.br/direitoepolitica - ISSN 1980-7791.

controle de informações exacerbadamente veiculadas na internet. Assim nos ensina Patricia Peck Pinheiro:

A sociedade digital já não é uma sociedade de bens. É uma sociedade de serviços em que a posse da informação prevalece sobre a posse dos bens de produção. Essa característica faz com que a proteção do direito à informação seja um dos princípios basilares do Direito Digital, assim como a proteção de seu contradireito, ou seja, do direito à não informação ${ }^{14}$.

A Lei $12.965 / 2014$ elenca em seu artigo 30 os princípios que disciplinam o uso da internet no Brasil. O inciso II determina a proteção da privacidade, ou seja, o direito de todo indivíduo em ter a sua vida particular, as informações que considera íntimas, resguardadas. Compreende-se, assim, que na sociedade democrática como a brasileira "o direito à não informação traz um limite ao direito de informar no qual o valor protegido é a privacidade do indivíduo"15.

Pensar o cidadão desvinculado da era informática é, talvez, impossível na atualidade. As facilidades e, em muitos casos, a necessidade de os indivíduos estarem inseridos nesse novo mundo fazem com que a internet seja vista como uma ferramenta que conduz o ser humano ao conhecimento, ao trabalho e ao próprio crescimento pessoal. $\mathrm{O}$ artigo 70 do Marco Civil da Internet determina:

Artigo 70 O acesso à internet é essencial ao exercício da cidadania, e ao usuário são assegurados os seguintes direitos:

I - inviolabilidade da intimidade e da vida privada, sua proteção e indenização pelo dano material ou moral decorrente de sua violação;

II - inviolabilidade e sigilo do fluxo de suas comunicações pela internet, salvo por ordem judicial, na forma da lei;

III - inviolabilidade e sigilo de suas comunicações privadas armazenadas, salvo por ordem judicial;

\footnotetext{
${ }^{14}$ PINHEIRO, Patrícia Peck. Direito digital. 4 ed. São Paulo: Saraiva, 2010, p. 82.

15 PINHEIRO, Patrícia Peck. Direito digital. p. 83.
} 
DE CASTRO, André Giovane; FORNASIER, Mateus de Oliveira, Benedito Silva e DE MELLO, Larissa Fernandes Ranieri. Leis brasileiras e atuação dos tribunais quanto à possibilidade de indenização contra danos à privacidade do indivíduo. Revista Eletrônica Direito e Política, Programa de PósGraduação Stricto Sensu em Ciência Jurídica da UNIVALI, Itajaí, v.10, n.4, 30 quadrimestre de 2015. Disponível em: www.univali.br/direitoepolitica - ISSN 1980-7791.

$$
(\ldots)^{16}
$$

O cidadão, como usuário da internet, encontra nesse instrumento tecnológico mecanismos essenciais para o seu desenvolvimento, com primazia a sua atuação enquanto integrante do corpo social. A cidadania, portanto, tem como pressuposto que o ser humano tenha acesso à informação, assim como o direito à livre expressão, mas, indubitavelmente, assegurada a inviolabilidade de sua intimidade, tutelada pelos direitos da personalidade.

Conforme Paulo José da Costa Júnior:

(...) as modernas técnicas de informática atendem relevantes finalidades sociais. Não se pode lamentar jamais o seu progresso. Muito pelo contrário, deverão elas ser louvadas sobremaneira, por todos os benefícios que vêm produzindo, inclusive na prevenção e na repressão ao delito. O que se haverá de censurar, tão somente, é o abuso da informática, ainda que de natureza culposa a conduta (negligência, imperícia), já que o seu uso indiscriminado e ilimitado poderá converter-se num autêntico "carcereiro da personalidade do homem"17.

\subsection{Responsabilização por danos resultantes da violação do direito à privacidade}

Embora a legislação confira vários direitos aos usuários, é necessário ter consciência da forma como se utiliza os mecanismos disponíveis na internet. A liberdade de expressão, que encontra amparo na Constituição Federal, em seu artigo 50, IV, precisa ser compreendida, vista sua complexidade. É assegurada a possibilidade de as pessoas se expressarem virtualmente; contudo, há ressalvas quanto ao teor, uma vez que termos racistas ou preconceituosos, que incitem à

\footnotetext{
16 BRASIL. Marco Civil da Internet. Lei 12.965, de 23 de abril de 2014. Disponível em: <http://www.planalto.gov.br/ccivil_03/_ato2011-2014/2014/lei/l12965.htm>. Acesso em: 07 mar. 2015.

17 SCORZELLI, Patrícia. A comunidade cibernética e o direito. Rio de Janeiro: Lumen Juris, 1997, p. 24-25.
} 
DE CASTRO, André Giovane; FORNASIER, Mateus de Oliveira, Benedito Silva e DE MELLO, Larissa Fernandes Ranieri. Leis brasileiras e atuação dos tribunais quanto à possibilidade de indenização contra danos à privacidade do indivíduo. Revista Eletrônica Direito e Política, Programa de PósGraduação Stricto Sensu em Ciência Jurídica da UNIVALI, Itajaí, v.10, n.4, 30 quadrimestre de 2015. Disponível em: www.univali.br/direitoepolitica - ISSN 1980-7791.

violência ou, mesmo, que exponham a intimidade de outro indivíduo na rede mundial de computadores geram sanções nas esferas civil e criminal.

Somente positivar os direitos da personalidade, portanto, não faz cessar os prejuízos morais e/ou materiais. Em virtude disso, o ordenamento jurídico brasileiro determinou a responsabilização de quem vier a violar a intimidade, como forma de punir quem atuou de modo contrário ao que preceitua a legislação.

Conforme conceitua José Adércio Leite Sampaio:

O dano patrimonial consiste na lesão de interesses pecuniários de uma pessoa, na diminuição, perda ou deterioração de bens materiais que Ihes pertenciam e que fossem susceptíveis de avaliação em dinheiro. Em uma fórmula sintética: na diminuição de seu patrimônio, real ou potencial $^{18}$.

Já o dano moral "consiste na lesão de interesses extrapatrimoniais da pessoa física ou jurídica, provocada pelo ato lesivo" ${ }^{19}$.

Marcel Leonardi destaca que:

(...) não se deve entender a tutela da privacidade como a proteção exclusiva de um indivíduo, mas sim como uma proteção necessária para a manutenção da estrutura social. A privacidade não é valiosa apenas para a vida privada de cada indivíduo, mas também para a vida pública e comunitária ${ }^{20}$.

É notório, dessa forma, que garantir uma tutela aos indivíduos que tiverem a sua privacidade violada significa promover uma regulação da própria vivência social. Assim, além de efetivar o direito do próprio sujeito, objetiva-se a instituição de um convívio coletivo propenso ao respeito, limitando o ser humano na divulgação

\footnotetext{
18 SAMPAIO, José Adércio Leite. Direito à intimidade e à privacidade: uma visão jurídica da sexualidade, da família, da comunicação e informações pessoais, da vida e da morte. p. 428.

${ }^{19}$ SAMPAIO, José Adércio Leite. Direito à intimidade e à privacidade: uma visão jurídica da sexualidade, da família, da comunicação e informações pessoais, da vida e da morte. p. 430.

${ }^{20}$ LEONARDI, Marcel. Tutela e privacidade na internet. São Paulo: Saraiva, 2011, p. 122.
} 
DE CASTRO, André Giovane; FORNASIER, Mateus de Oliveira, Benedito Silva e DE MELLO, Larissa Fernandes Ranieri. Leis brasileiras e atuação dos tribunais quanto à possibilidade de indenização contra danos à privacidade do indivíduo. Revista Eletrônica Direito e Política, Programa de PósGraduação Stricto Sensu em Ciência Jurídica da UNIVALI, Itajaí, v.10, n.4, 30 quadrimestre de 2015. Disponível em: www.univali.br/direitoepolitica - ISSN 1980-7791.

de informações consideradas íntimas e, consequentemente, prezando pela privacidade.

Paulo Lôbo compreende que:

A inserção constitucional dos direitos da personalidade e dos danos morais consagra a evolução pela qual ambos os institutos jurídicos têm passado. Os direitos da personalidade, por serem não patrimoniais, encontram excelente campo de aplicação nos danos morais, que têm a mesma natureza não patrimonial. Ambos têm por objeto bens integrantes da interioridade da pessoa, que não dependem da relação com os essenciais à realização da pessoa, ou seja, aquilo que é inato à pessoa e deve ser tutelado pelo direito ${ }^{21}$.

O instituto legal, diante disso, visa a proteger a vida íntima do sujeito de direito, isto é, fatos, situações e acontecimentos que a pessoa almeja ter apenas para si o conhecimento, garantindo-lhe, juridicamente, as medidas necessárias para culpabilizar o indivíduo. A partir disso, determina o artigo 21 do Código Civil Brasileiro de 2002: "A vida privada da pessoa natural é inviolável, e o juiz, a requerimento do interessado, adotará as providências necessárias para impedir ou fazer cessar ato contrário a esta norma"22.

Lôbo interpreta que:

Em razão de sua visceral interdependência com os direitos da personalidade, os danos morais nunca se apresentam como reparação, pois a lesão ao direito da personalidade não pode ser mensurada economicamente, como se dá com os demais direitos subjetivos. Por isso, a indenização tem função compensatória, que não pode ser simbólica, para que a compensação seja efetiva e produza impacto negativo no lesante, nem demasiada, para não conduzir ao

${ }^{21}$ LÔBO, Paulo. Danos morais e direitos da personalidadeJus Navigandi, Teresina, ano 8, n. 119, 31 out. 2003. Disponível em: Disponível em: <http://jus.com.br/artigos/4445>. Acesso em: 08 mar. 2015.

${ }^{22}$ BRASIL. Código Civil e Constituição Federal e legislação complementar: miniobra coletiva de autoria da Editora Saraiva com a colaboração de Luiz Roberto Curia, Livia Céspedes e Juliana Nicoletti. 
DE CASTRO, André Giovane; FORNASIER, Mateus de Oliveira, Benedito Silva e DE MELLO, Larissa Fernandes Ranieri. Leis brasileiras e atuação dos tribunais quanto à possibilidade de indenização contra danos à privacidade do indivíduo. Revista Eletrônica Direito e Política, Programa de PósGraduação Stricto Sensu em Ciência Jurídica da UNIVALI, Itajaí, v.10, n.4, 30 quadrimestre de 2015. Disponível em: www.univali.br/direitoepolitica - ISSN 1980-7791.

enriquecimento sem causa do lesado. [...] Deve o juiz valerse do princípio da proporcionalidade, tendo em vista serem os direitos atingidos muito mais valiosos que os bens $\mathrm{e}$ interesses econômicos, cuja lesão leva à restituição ${ }^{23}$.

Percebe-se que a pecúnia não é o centro do debate no que se refere ao ato de responsabilizar quem desrespeitou a norma. Ela é, sim, o complemento, ou seja, o patrimônio do indivíduo é utilizado como forma de punir, mas o objetivo primordial da lei é garantir a privacidade, o respeito à pessoa. Para isso, o valor deve ser, mesmo que complicado de definir, proporcional à lesão.

Nesse tocante, defende Marcel Leonardi:

É praticamente pacífico o entendimento da doutrina e da jurisprudência no sentido de que, ao arbitrar o valor da indenização por dano moral, o julgador deve agir com ponderação, fixando quantia razoável, tendo em vista que um valor ínfimo representaria verdadeiro incentivo ao ato ilícito e que um valor extremamente elevado implicaria enriquecimento sem causa ${ }^{24}$.

O Direito Digital, portanto, que a cada ano vem se consolidando como um ramo próprio da atual conjuntura, tem como dever a regulação dos atos realizados a partir de plataformas como a internet. Nesse viés, a área trabalha, dentre outros, com o Marco Civil da Internet e a responsabilização decorrente de violação do direito à privacidade.

O artigo 10 da Lei 12.965/2014 regula:

Artigo 10. A guarda e a disponibilização dos registros de conexão e de acesso a aplicações de internet de que trata esta Lei, bem como de dados pessoais e do conteúdo de comunicações privadas, devem atender à preservação da intimidade, da vida privada, da honra e da imagem das partes direta ou indiretamente envolvidas ${ }^{25}$.

\footnotetext{
${ }^{23}$ LÔBO, Paulo. Danos morais e direitos da personalidade.

${ }^{24}$ LEONARDI, Marcel. Tutela e privacidade na internet. p. 224.

25 BRASIL. Marco Civil da Internet. Lei 12.965, de 23 de abril de 2014.
} 
DE CASTRO, André Giovane; FORNASIER, Mateus de Oliveira, Benedito Silva e DE MELLO, Larissa Fernandes Ranieri. Leis brasileiras e atuação dos tribunais quanto à possibilidade de indenização contra danos à privacidade do indivíduo. Revista Eletrônica Direito e Política, Programa de PósGraduação Stricto Sensu em Ciência Jurídica da UNIVALI, Itajaí, v.10, n.4, 30 quadrimestre de 2015. Disponível em: www.univali.br/direitoepolitica - ISSN 1980-7791.

Trata-se de um dispositivo legal direcionado a responsabilizar quem, descumprindo-o, vier a tornar público informações inerentes à pessoa humana, caso esta não houver manifestado consentimento em tal atitude. Nesse tocante, encontra-se o direito à não informação, isto é, do provedor de internet não divulgar dados relativos à intimidade do sujeito que porventura tenha contratado serviço tecnológico.

Os provedores, a partir dessa norma, devem guardar o registro de conexão dos usuários, ou seja, as informações referentes à data e hora de início e término da utilização, assim como a duração e o endereço de IP (Protocolo de Internet) utilizado pelo terminal para o envio e recebimento de pacotes de dados.

Com o entendimento do direito à privacidade como norteador das novas relações jurídicas, destaca Patricia Peck Pinheiro:

É evidente que o direito à privacidade constitui um limite natural ao direito à informação. No entanto, não há lesão a direito se houver consentimento, mesmo que implícito, na hipótese em que a pessoa demonstra de algum modo interesse em divulgar aspectos da própria vida ${ }^{26}$.

No âmbito da legislação brasileira, há a obrigação de não lesar e, em transgredindo-a, é punido com o dever de indenizar, uma vez que tenha prejudicado injustamente outrem, seja em aspecto material ou moral. No dano não patrimonial, como é o caso quanto aos direitos da personalidade, o objetivo é atenuar o sofrimento de quem fora lesionado, assim como coibir a reincidência na prática de tal ofensa.

\section{POSICIONAMENTO DOS TRIBUNAIS SUPERIORES}

A informação é um instrumento fundamental em uma sociedade democrática. Tornar um fato conhecido pelo público é necessário quando se almeja zelar pela comunicação e pelo fortalecimento da cidadania, pois os meios de comunicação

\footnotetext{
26 PINHEIRO, Patrícia Peck. Direito digital. p. 85.
} 
DE CASTRO, André Giovane; FORNASIER, Mateus de Oliveira, Benedito Silva e DE MELLO, Larissa Fernandes Ranieri. Leis brasileiras e atuação dos tribunais quanto à possibilidade de indenização contra danos à privacidade do indivíduo. Revista Eletrônica Direito e Política, Programa de PósGraduação Stricto Sensu em Ciência Jurídica da UNIVALI, Itajaí, v.10, n.4, 30 quadrimestre de 2015. Disponível em: www.univali.br/direitoepolitica - ISSN 1980-7791.

fornecem condições para que a sociedade se torne mais culta, com compreensão da realidade e capacidade de discernimento e argumentação. Há, contudo, um debate muito intenso acerca da colisão entre dois direitos constitucionais: o da liberdade de expressão e o da privacidade ${ }^{27}$.

Nas últimas décadas, os tribunais brasileiros tiveram que enfrentar a discussão e dar, por consequência, parecer direcionado à superioridade da liberdade de expressão ou à inviolabilidade dos direitos da personalidade. De um lado, portanto, está o veículo de comunicação defendendo o seu direito de informar e, de outro, o personagem citado na notícia requerendo indenização em virtude de ter sua privacidade violada.

Nesse confronto de direitos, o Superior Tribunal de Justiça (STJ) julgou, em 28 de maio de 2013, o Recurso Especial 1.334.097/RJ:

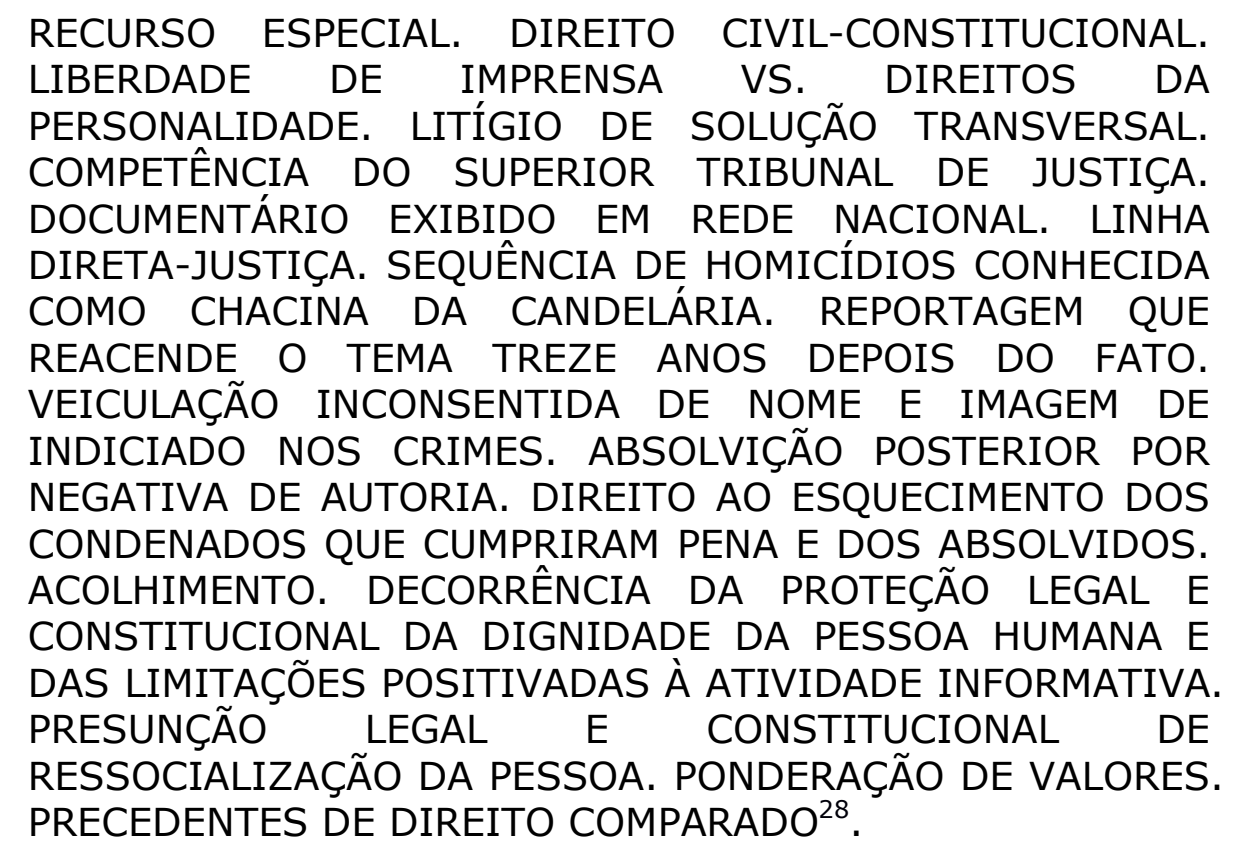

\footnotetext{
${ }^{27}$ BRASIL. Constituição da República Federativa do Brasil de 1988.

${ }^{28}$ BRASIL. Superior Tribunal de Justiça. Recurso Especial no 1.334.097/RJ. Brasília, DF, 28 de maio de 2013. Disponível em: <https://ww2.stj.jus.br/processo/revista/documento/mediado/?componente=ITA\&sequencial=12 39004\&num_registro $=201201449107 \&$ data $=20130910 \&$ formato $=P D F>$. Acesso em: 14 mar. 2015.
} 
DE CASTRO, André Giovane; FORNASIER, Mateus de Oliveira, Benedito Silva e DE MELLO, Larissa Fernandes Ranieri. Leis brasileiras e atuação dos tribunais quanto à possibilidade de indenização contra danos à privacidade do indivíduo. Revista Eletrônica Direito e Política, Programa de PósGraduação Stricto Sensu em Ciência Jurídica da UNIVALI, Itajaí, v.10, n.4, 30 quadrimestre de 2015. Disponível em: www.univali.br/direitoepolitica - ISSN 1980-7791.

O STJ, ao analisar o processo de contestação supracitado, entendeu que a liberdade de imprensa, em não sendo absoluta, encontra limitações, como a preservação dos chamados direitos da personalidade, entre os quais se incluem os direitos à honra, à imagem, à privacidade e à intimidade. O mesmo entendimento já havia sido declarado pelo ministro Raul Araújo, em 12 de junho de 2012, no REsp 801.109/DF ${ }^{29}$.

Ao discorrer sobre seu voto, o ministro Araújo declarou:

O primeiro desses fatores de limitação reside no compromisso com a verdade. Entende-se assegurado ao jornalista emitir opinião e formular críticas, ainda que desfavoráveis e contundentes, contra qualquer pessoa ou autoridade, desde que fundadas na narração de fatos verídicos. Porém, quando os fatos noticiados não são verdadeiros, pode haver abuso do direito de informar por parte do jornalista. (...) Assim, se a matéria falsa veiculada na imprensa for publicada dolosamente ou com manifesta desconsideração negligente da verdade, poderá ficar caracterizado o dever de reparar eventual dano.

A indenização resulta da narração desvinculada da verdade dos fatos. Ao mesmo tempo em que os meios de comunicação são assegurados do direito à liberdade de expressão e de informar aquilo que é de interesse público, eles têm para si a responsabilidade de garantir ao leitor e aos atores da notícia a transmissão coerente e verídica do fato, seja apenas relatado ou comentado.

Fábio Siebeneichler de Andrade, ao discorrer sobre o assunto, destaca que:

Cabe, na verdade, aos órgãos de imprensa demonstrar, ao menos em suas linhas gerais, a existência do interesse público, a ponto de exigir que em uma determinada matéria seja veiculado comentário excepcionalmente crítico sobre pessoa que não possua dimensão pública, ou em casos em que seja exibida sua imagem em circunstâncias desabonadoras, ou quando as pessoas não estiverem

\footnotetext{
${ }^{29}$ BRASIL. Superior Tribunal de Justiça. Recurso Especial no 801.109/DF. Brasília, DF, 12 de junho de 2012. Disponível em: <https://ww2.stj.jus.br/processo/revista/documento/mediado/?componente=ITA\&sequencial=11 49023\&num_registro $=200501951627 \&$ data $=20130312 \&$ formato $=P D F>$. Acesso em: 14 mar. 2015.
} 
DE CASTRO, André Giovane; FORNASIER, Mateus de Oliveira, Benedito Silva e DE MELLO, Larissa Fernandes Ranieri. Leis brasileiras e atuação dos tribunais quanto à possibilidade de indenização contra danos à privacidade do indivíduo. Revista Eletrônica Direito e Política, Programa de PósGraduação Stricto Sensu em Ciência Jurídica da UNIVALI, Itajaí, v.10, n.4, 30 quadrimestre de 2015. Disponível em: www.univali.br/direitoepolitica - ISSN 1980-7791.

diretamente vinculadas a um evento de repercussão. Este critério de ponderação tem sido adotado pela jurisprudência, que se ocupa em distinguir situações em que a pessoa exerce atividade pública, - e pode, portanto, ser objeto de crítica, ter sua imagem relacionada à circunstância fática notória ou de interesse social e informativo a ela vinculada -, daquelas em que a pessoa é retratada em sua esfera privada $^{30}$

Em posição considerada mais tolerante, porém, o ministro Luis Felipe Salomão mencionou que:

O dever de veracidade ao qual estão vinculados os órgãos de imprensa não deve consubstanciar-se dogma absoluto, ou condição peremptoriamente necessária à liberdade de imprensa, mas um compromisso ético com a informação verossímil, o que pode, eventualmente, abarcar informações não totalmente precisas ${ }^{31}$.

Compreende-se, desse modo, que analisar a veracidade não deve ser supremo ao passo de se instituir ou perceber ato de censura, uma vez que colide com os fundamentos do Estado Democrático de Direito. É necessário que haja a intenção de noticiar a verdade, mesmo que não sejam inseridas expressões precisas.

Conforme o relator ministro Luis Felipe Salomão, no julgamento do REsp 1.334.097/RJ:

Agora, uma vez mais, o conflito entre liberdade de informação e direitos da personalidade ganha a tônica da modernidade, analisado por outro prisma, desafiando o julgador a solucioná-lo a partir de nova realidade social, ancorada na informação massificada que, diariamente, se choca com a invocação de novos direitos, hauridos que sejam dos já conhecidos direitos à honra, à privacidade e à intimidade, todos eles, por sua vez, resultantes da proteção constitucional conferida à dignidade da pessoa humana ${ }^{32}$.

\footnotetext{
30 ANDRADE, Fábio Siebeneichler de. A tutela dos direitos da personalidade no direito brasileiro em perspectiva atual. p. 114.

${ }^{31}$ BRASIL. Superior Tribunal de Justiça. Recurso Especial no 1.334.097/RJ.

32 BRASIL. Superior Tribunal de Justiça. Recurso Especial no 1.334.097/RJ.
} 
DE CASTRO, André Giovane; FORNASIER, Mateus de Oliveira, Benedito Silva e DE MELLO, Larissa Fernandes Ranieri. Leis brasileiras e atuação dos tribunais quanto à possibilidade de indenização contra danos à privacidade do indivíduo. Revista Eletrônica Direito e Política, Programa de PósGraduação Stricto Sensu em Ciência Jurídica da UNIVALI, Itajaí, v.10, n.4, 30 quadrimestre de 2015. Disponível em: www.univali.br/direitoepolitica - ISSN 1980-7791.

A partir desse dilema, complementa Sergio Cavalieri Filho:

Os nossos melhores constitucionalistas, baseados na jurisprudência da Suprema Corte Alemã, indicam o princípio da proporcionalidade como sendo o meio mais adequado para se solucionar eventuais conflitos entre a liberdade de comunicação e os direitos de personalidade ${ }^{33}$.

No presente caso, do Recurso Especial 1.334.097/RJ, o autor da ação por danos morais, Jurandir Gomes de França, inocentado no crime nacionalmente conhecido como Chacina da Candelária, buscava a proclamação do seu direito ao esquecimento, ou seja, de não ser lembrado contra sua vontade. A ação decorre da veiculação de reportagem no programa Linha Direta - Justiça, transmitida pela Rede Globo de Televisão, na qual o autor, ao ser procurado pela emissora, não autorizou a divulgação de informações ou imagens referentes a sua pessoa. No entanto, conforme os autos do processo, houve a divulgação, reacendendo na sociedade o ódio contra ele.

O julgamento, à vista disso, focou-se a analisar a adequação do direito ao esquecimento. A sua previsão constata-se na legislação penal brasileira, uma vez que há o interesse de proteger os agentes que foram condenados e já cumpriram suas penas. A intenção, dessa forma, é não retomar na sociedade o ódio, o desprezo e a sensação de violência para com o criminoso, principalmente se houver o acusado sido inocentado.

Fábio Siebeneichler de Andrade, ao tratar sobre o direito ao esquecimento, explica que se pretende "evitar que fatos ocorridos em seu passado sejam tornados públicos, em especial a fim de evitar que a mídia resgate escândalos ou casos passionais" ${ }^{\prime 34}$.

Um debate bastante acirrado, que também se insere nesse julgado e deve ser analisado, compreende o poder da mídia frente à sociedade. A indústria de

${ }^{33}$ CAVAlieri FILHO, Sergio. Programa de Responsabilidade Civil. 6 ed. São Paulo: Malheiros, 2005. p. 130.

34 ANDRADE, Fábio Siebeneichler de. A tutela dos direitos da personalidade no direito brasileiro em perspectiva atual. p. 120. 
DE CASTRO, André Giovane; FORNASIER, Mateus de Oliveira, Benedito Silva e DE MELLO, Larissa Fernandes Ranieri. Leis brasileiras e atuação dos tribunais quanto à possibilidade de indenização contra danos à privacidade do indivíduo. Revista Eletrônica Direito e Política, Programa de PósGraduação Stricto Sensu em Ciência Jurídica da UNIVALI, Itajaí, v.10, n.4, 30 quadrimestre de 2015. Disponível em: www.univali.br/direitoepolitica - ISSN 1980-7791.

comunicação, principalmente decorrente da liberdade de expressão, promove a supremacia dos veículos no que tange à opinião pública.

A imprensa, enquanto grupo controlador da informação, detém o poder dos conteúdos a serem transmitidos ao seu público. Considerada como o quarto poder, a mídia é, atualmente, formada de poderosos atores, livres de censura, que repercutem a notícia conforme o seu interesse, muitas vezes ultrapassando o mero direito e dever de informar.

Merece salientar, no entanto, a importância da mídia em uma sociedade democrática. De acordo com o ministro Celso de Mello, do Supremo Tribunal Federal, no julgamento da Reclamação 9.428/DF, em 10 de dezembro de 2009:

(...) no contexto de uma sociedade fundada em bases democráticas, mostra-se intolerável a repressão estatal ao pensamento, ainda mais quando a crítica - por mais dura que seja - revele-se inspirada pelo interesse coletivo e decorra da prática legítima, como sucede na espécie, de uma liberdade pública de extração eminentemente constitucional ${ }^{35}$.

Os veículos de comunicação, dessa forma, passam a ser definidos como instrumentos de persuasão, uma vez que propiciam a constituição de uma opinião. Em virtude disso, há a discussão sobre a influência da mídia no decorrer do processo judicial e, além deste, de emitir juízo de valor, condenando ou absolvendo o indivíduo, protagonista de determinada reportagem.

Além disso, de acordo com a decisão do STJ, outro aspecto que merece ser discutido é a historicidade da notícia jornalística, como é o caso mencionado, em razão de que tenha ocorrido em 23 de julho de 1993. Em função dessa característica e, em se tratando de jornalismo policial, a sua elaboração deve ser vista com cautela. Há, assim, a preocupação para que a veiculação de notícias não venha a violar a privacidade do indivíduo.

${ }^{35}$ BRASIL. Supremo Tribunal Federal. Reclamação no 9.428/DF. Brasília, DF, 10 de dezembro de 2009. 
DE CASTRO, André Giovane; FORNASIER, Mateus de Oliveira, Benedito Silva e DE MELLO, Larissa Fernandes Ranieri. Leis brasileiras e atuação dos tribunais quanto à possibilidade de indenização contra danos à privacidade do indivíduo. Revista Eletrônica Direito e Política, Programa de PósGraduação Stricto Sensu em Ciência Jurídica da UNIVALI, Itajaí, v.10, n.4, 30 quadrimestre de 2015. Disponível em: www.univali.br/direitoepolitica - ISSN 1980-7791.

O relator conclui:

A explícita contenção constitucional à liberdade de informação, fundada na inviolabilidade da vida privada, intimidade, honra, imagem e, de resto, nos valores da pessoa e da família, prevista no artigo 220, $\S 10$, artigo 221 e no $\S 3^{\circ}$ do artigo 222 da Carta de 1988, parece sinalizar que, no conflito aparente entre esses bens jurídicos de especialíssima grandeza, há, de regra, uma inclinação ou predileção constitucional para soluções protetivas da pessoa humana ${ }^{36}$.

O Tribunal de Justiça do Estado do Rio Grande do Sul, em 29 de maio de 2008, também precisou se dedicar à Apelação Cível no $70021749064^{37}$, abordando a temática do direito à privacidade. No caso em voga, os requerentes alegaram que, depois de contratarem uma empresa para fornecer internet via rádio, foram comunicados por terceira pessoa, também contratante da referida empresa, que os seus arquivos particulares podiam ser visualizados em outros computadores, como se estivessem em rede.

A partir disso, pleitearam indenização em razão de terem a privacidade invadida, uma vez que arquivos particulares, muitos contendo matéria relativa a casos que tramitam em segredo de justiça, pois atuam como advogados, estavam dispostos a outros consumidores da respectiva empresa de internet. Para tanto, ao julgar, o relator-desembargador Paulo Roberto Lessa Franz discorreu que "deve a demandada responder pelos danos decorrentes da prestação de serviço defeituosa, restando evidente o dever de indenizar" ${ }^{\prime 38}$.

Verifica-se, portanto, que os tribunais têm conferida valiosa consideração aos direitos da personalidade. O sistema democrático abre espaço para que as pessoas se expressem; inclusive, aos meios de comunicação. No entanto,

\footnotetext{
${ }^{36}$ BRASIL. Superior Tribunal de Justiça. Recurso Especial no 1.334.097/RJ.

${ }^{37}$ BRASIL. Tribunal de Justiça do Estado do Rio Grande do Sul. Apelação Cível no $\mathbf{7 0 0 2 1 7 4 9 0 6 4 .}$ Porto Alegre, RS, 29 de maio de 2008. Disponível em: <http://migre.me/pJjUg>. Acesso em: $1^{\circ}$ mai. 2015.

38 BRASIL. Tribunal de Justiça do Estado do Rio Grande do Sul. Apelação Cível no 70021749064.
} 
DE CASTRO, André Giovane; FORNASIER, Mateus de Oliveira, Benedito Silva e DE MELLO, Larissa Fernandes Ranieri. Leis brasileiras e atuação dos tribunais quanto à possibilidade de indenização contra danos à privacidade do indivíduo. Revista Eletrônica Direito e Política, Programa de PósGraduação Stricto Sensu em Ciência Jurídica da UNIVALI, Itajaí, v.10, n.4, 30 quadrimestre de 2015. Disponível em: www.univali.br/direitoepolitica - ISSN 1980-7791.

salienta-se o respeito à vida privada de cada indivíduo, uma vez que a Constituição Federal de 1988 determina no artigo 10, III, como princípio supremo a dignidade da pessoa humana ${ }^{39}$. A privacidade, ora intensamente debatida, constitui-se como um direito inerente ao ser humano e, ao se romper o limite da informação, há o dever de responsabilização pelos danos causados.

\section{CONSIDERAÇÕES FINAIS}

Após séculos considerando o patrimônio como tema central do Direito, a legislação brasileira foi direcionada a pensar na tutela conferida aos sujeitos de direito. A Constituição Federal de 1988, ao consolidar o processo de redemocratização, instituiu a privacidade como garantia aos seres humanos, principalmente em virtude da crescente informação vivenciada nas últimas décadas a partir do avanço tecnológico.

Regular as informações e os dados veiculados nos meios de comunicação, inclusive nas redes sociais, é um dos principais objetivos, portanto, de leis que venham ao encontro do respeito à vida privada. Com a era da informação, surgem problemas concernentes à violação da privacidade, provocando, consequentemente, danos à dignidade da pessoa humana, tratada como princípio supremo no texto constitucional.

Além do Código Civil de 2002, o Marco Civil da Internet, sancionado em 2014, veio regular o uso da internet no Brasil. A rede mundial de computadores é, como analisado, o norte desta Lei $12.965 / 2014$, determinando princípios, direitos e deveres a quem utiliza e fornece o serviço.

Os tribunais brasileiros, conforme análise supramencionada, têm entendido como válida a discussão e, por consequência, precisam julgar em muitos casos o conflito entre dois direitos constitucionais: o da privacidade e o da liberdade de expressão. Há, à vista disso, um debate concernente à limitação de ambos os

\footnotetext{
${ }^{39}$ BRASIL. Constituição da República Federativa do Brasil de 1988.
} 
DE CASTRO, André Giovane; FORNASIER, Mateus de Oliveira, Benedito Silva e DE MELLO, Larissa Fernandes Ranieri. Leis brasileiras e atuação dos tribunais quanto à possibilidade de indenização contra danos à privacidade do indivíduo. Revista Eletrônica Direito e Política, Programa de PósGraduação Stricto Sensu em Ciência Jurídica da UNIVALI, Itajaí, v.10, n.4, 30 quadrimestre de 2015. Disponível em: www.univali.br/direitoepolitica - ISSN 1980-7791.

direitos, uma vez que o Brasil se constitui enquanto Estado Democrático de Direito e, em razão disso, contrário à censura.

A dignidade da pessoa humana, portanto, passa a ser o divisor nessa discussão, prevalecendo o respeito ao ser humano desde que seja concretamente verificada a abusividade da informação difundida. Assim, percebe-se que a responsabilização acerca do direito à privacidade, como integrante dos direitos da personalidade, se dá em consonância com os resultados lesivos à pessoa.

Verifica-se, dessa maneira, a possibilidade de responsabilizar quem violar a privacidade de outrem. A pecúnia é utilizada como forma de punir, embora o almejo central seja atenuar o sofrimento de quem fora lesionado, assim como coibir a reincidência na prática de tal ofensa. O sistema jurídico, em razão disso, deve atender às demandas e condenar caso forem constatados danos morais e/ou materiais.

\section{REFERÊNCIAS DAS FONTES CITADAS}

ANDRADE, Fábio Siebeneichler de. A tutela dos direitos da personalidade no direito brasileiro em perspectiva atual. Revista Derecho del Estado. 30 ed. Bogotá: 2013.

BRASIL. Código Civil e Constituição Federal e legislação complementar: miniobra coletiva de autoria da Editora Saraiva com a colaboração de Luiz Roberto Curia, Livia Céspedes e Juliana Nicoletti. 21 ed. São Paulo: Saraiva, 2015.

BRASIL. Constituição (1988). Constituição da República Federativa do Brasil. Brasília: Senado Federal, Subsecretaria de Edições Técnicas, 2012.

BRASIL. Marco Civil da Internet. Lei 12.965, de 23 de abril de 2014. Disponível em: <http://www.planalto.gov.br/ccivil_03/_ato20112014/2014/lei/l12965.htm>. Acesso em: 07 mar. 2015.

BRASIL. Supremo Tribunal Federal. Reclamação no 9.428/DF. Liberdade de imprensa. Decisão liminar. Proibição de reprodução de dados relativos ao autor de ação inibitória ajuizada contra empresa jornalística. Ato decisório fundado na 
DE CASTRO, André Giovane; FORNASIER, Mateus de Oliveira, Benedito Silva e DE MELLO, Larissa Fernandes Ranieri. Leis brasileiras e atuação dos tribunais quanto à possibilidade de indenização contra danos à privacidade do indivíduo. Revista Eletrônica Direito e Política, Programa de PósGraduação Stricto Sensu em Ciência Jurídica da UNIVALI, Itajaí, v.10, n.4, 30 quadrimestre de 2015. Disponível em: www.univali.br/direitoepolitica - ISSN 1980-7791.

expressa invocação da inviolabilidade constitucional dos direitos da personalidade, notadamente o da privacidade, mediante proteção de sigilo legal de dados cobertos por segredo de justiça. Contraste teórico entre liberdade de imprensa e os direitos previstos nos arts. 50, incs. X e XII, e 220, caput, da CF. Ofensa à autoridade do acórdão proferido na ADPF no 130, que deu por não recebida a Lei de Imprensa. Não ocorrência. Matéria não decidida na ADPF. Processo de reclamação extinto, sem julgamento de mérito. Votos vencidos. Reclamante: S. A O Estado de São Paulo. Reclamado: Tribunal de Justiça do Distrito Federal e dos Territórios. Relator: Ministro Cezar Peluso. Brasília, DF, 10 de dezembro de 2009.2 Disponível em: <http://redir.stf.jus.br/paginadorpub/paginador.jsp?docTP=AC\&docID =612474> . Acesso em: 19 mar. 2015.

BRASIL. Superior Tribunal de Justiça. Recurso Especial no 801.109/DF. Recurso especial. Civil. Danos morais. Matéria jornalística ofensiva. Lei de Imprensa (Lei 5.250/67). ADPF no 130/DF. Efeito vinculante. Observância. Liberdade de imprensa e de informação (CF, arts. 50, IV, IX e XIV, e 220, caput, $\S \S 1^{\circ}$ e $2^{\circ}$ ). Crítica jornalística. Ofensas à imagem e à honra de magistrado (CF, art. 50, $\mathrm{V}$ e X). Abuso do exercício da liberdade de imprensa não configurado. Recorrente: Editora Abril S/A. Recorrido: Asdrúbal Zola Vasquez Cruxên. Relator: Ministro Raul Araújo. Brasília, DF, 12 de junho de 2012. Disponível em: <https://ww2.stj.jus.br/processo/revista/documento/mediado/?componente=ITA \&sequencial $=1149023 \&$ num_registro $=200501951627 \&$ data $=20130312$ \&formato $=$ PDF $>$. Acesso em: 14 mar. 2015.

BRASIL. Superior Tribunal de Justiça. Recurso Especial no 1.334.097/RJ. Recurso especial. Direito Civil-Constitucional. Liberdade de imprensa vs. Direitos da Personalidade. Litígio de solução transversal. Competência do Superior Tribunal de Justiça. Documentário exibido em rede nacional. Linha Direta-Justiça. Sequência de homicídios conhecida como Chacina da Candelária. Reportagem que reacende o tema treze anos depois do fato. Veiculação inconsentida de nome e imagem de indiciado nos crimes. Absolvição posterior por negativa de autoriza. Direito ao esquecimento dos condenados que cumpriram pena e dos absolvidos. Acolhimento. Decorrência da proteção legal e constitucional da dignidade da pessoa humana e das limitações positivadas à atividade informativa. Presunção legal e constitucional de ressocialização da pessoa. Ponderação de valores. Precedentes de direito comparado. Recorrente: Globo Comunicações e Participações S/A. Recorrido: Jurandir Gomes de França. Relator: Ministro Luis Felipe Salomão. Brasília, DF, 28 de maio de 2013. Disponível em: <https://ww2.stj.jus.br/processo/revista/documento/mediado/?componente=ITA \&sequencial $=1239004 \&$ num_registro $=201201449107 \&$ data $=20130910 \&$ formato =PDF $>$. Acesso em: 14 mar. 2015. 
DE CASTRO, André Giovane; FORNASIER, Mateus de Oliveira, Benedito Silva e DE MELLO, Larissa Fernandes Ranieri. Leis brasileiras e atuação dos tribunais quanto à possibilidade de indenização contra danos à privacidade do indivíduo. Revista Eletrônica Direito e Política, Programa de PósGraduação Stricto Sensu em Ciência Jurídica da UNIVALI, Itajaí, v.10, n.4, 30 quadrimestre de 2015. Disponível em: www.univali.br/direitoepolitica - ISSN 1980-7791.

BRASIL. Tribunal de Justiça do Estado do Rio Grande do Sul. Apelação Cível no 70021749064. Décima Câmara Cível. Apelação cível. Responsabilidade civil. Indenização por danos morais. Instalação de internet via rádio. Visualização dos arquivos profissionais e particulares dos autores por outro usuário da internet, como se estivessem em rede. Falha na prestação de serviço. Dever de indenizar. Apelante: Getec Sistemas de Segurança Ltda. Apelados: José Cândido de Azevedo Jordão e Rafael Osvaldo de Azevedo Lopes. Relator: Desembargador Paulo Roberto Lessa Franz. Porto Alegre, RS, 29 de maio de 2008. Disponível em: <http://migre.me/pjjUg>. Acesso em: 10 mai. 2015.

CAMPOS, Diogo Leite de. Lições de Direito da Personalidade. 2 ed. Coimbra: Universidade de Coimbra, 1992.

CAVAlieRI FILHO, Sergio. Programa de Responsabilidade Civil. 6 ed. São Paulo: Malheiros, 2005.

GAGLIANO, Pablo Stolze; FILHO, Rodolfo Pamplona. Novo curso de direito civil - Parte geral 1. 16 ed. São Paulo: Saraiva, 2014.

LEONARDI, Marcel. Tutela e privacidade na internet. São Paulo: Saraiva, 2011.

LÔBO, Paulo. Danos morais e direitos da personalidade. Jus Navigandi, Teresina, ano 8, n. 119, 31 out. 2003. Disponível em: <http://jus.com.br/artigos/444. Acesso em: 15 mai. 2015.

NICOLODI, Márcia. Os direitos da personalidade e a proteção da dignidade da pessoa humana. Ijuí, 2003, 84 p.

PINHEIRO, Patricia Peck. Direito digital. 4 ed. São Paulo: Saraiva, 2010. 472 p.

SAMPAIO, José Adércio Leite. Direito à intimidade e à privacidade: uma visão jurídica da sexualidade, da família, da comunicação e informações pessoais, da vida e da morte. Belo Horizonte: Del Rey, 1998, 616 p.

SCORZELLI, Patrícia. A comunidade cibernética e o direito. Rio de Janeiro: Lumen Juris, 1997, 98 p.

Submetido em: Outubro/2015

Aprovado em: Dezembro/2015 